\title{
A Memória do Atletismo nos Cursos de Educação Física da Universidade Federal de Santa Maria
}

\author{
Athletics Memory in Physical Education Courses at the Federal University of Santa Maria \\ Memoria del Atletismo en los Cursos de Educación Física de la Universidad Federal de Santa \\ María
}

Leandra Costa Da Costa ${ }^{\mathrm{I}}$, Matheus Francisco Saldanha Filho ${ }^{\mathrm{II}}$,Gislei José Scapin ${ }^{\mathrm{III}}$, Nestor Rossi Júnior ${ }^{\mathrm{IV}}$

\section{Resumo}

Este artigo tematiza a memória das disciplinas de Atletismo dos Cursos de Educação Física durante os 50 anos do Centro de Educação Física e Desportos da Universidade Federal de Santa Maria (CEFD/UFSM). Objetivamos apresentar o desenvolvimento das referidas disciplinas, trazendo para cena suas primeiras formas de organização curricular, a identificação de seus docentes, os materiais pedagógicos e a estrutura física utilizada para as aulas. Seguiu uma perspectiva histórica pautada por uma análise documental, bem como um diálogo com três professores aposentados que empreenderam uma carreira profissional como docentes das disciplinas em questão. Concluímos evidenciando a atualidade e as projeções para o desenvolvimento das disciplinas de Atletismo nos Cursos de Educação Física Licenciatura e Bacharelado do CEFD/UFSM, bem como as ações e projetos que estão em atividade tematizando o referido esporte.

Palavras-chave: Memória; Atletismo; Currículo

\begin{abstract}
This article focuses on the memory of the Athletics disciplines of Physical Education Courses during the 50 years of the Physical Education and Sports Center of the Federal University of Santa Maria (CEFD / UFSM). We aim to present the development of these disciplines, bringing to the scene their first forms and curricular organization, the identification of their teachers, the pedagogical materials and the physical structure used for the classes. It followed a historical perspective guided by a documentary analysis, as well as a dialogue with three retired teachers who embarked on a professional career as teachers of the subjects in question. We conclude by highlighting the timeliness and projections for the development of the Athletics disciplines in the Physical Education Courses Bachelor and Bachelor of CEFD / UFSM, as well as the actions and projects that are in operation with the theme of that sport.
\end{abstract}

Keywords: Memory; Athletics; Curriculum

\footnotetext{
${ }^{\text {I}}$ Universidade Federal de Santa Maria - UFSM - Endereço: Av. Roraima, número 1000, Bairro: Camobi, Prédio 51, Santa Maria, RS. CEP: $97105-900$ - e-mail: lcostadacosta@hotmail.com

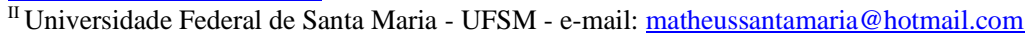

${ }^{\text {III } U n i v e r s i d a d e ~ F e d e r a l ~ d e ~ S a n t a ~ M a r i a ~-~ U F S M ~-~ e-m a i l: ~ g j s c a p i n @ ~ g m a i l . c o m ~}$

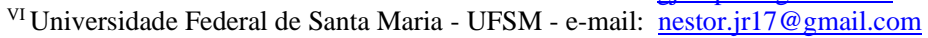




\section{Resumen}

Este artículo se centra en la memoria de las disciplinas del Atletismo de los Cursos de Educación Física durante los 50 años del Centro de Educación Física y Deportes de la Universidad Federal de Santa María (CEFD / UFSM). Nuestro objetivo es dar a conocer el desarrollo de estas disciplinas, trayendo al escenario sus primeras formas y organización curricular, la identificación de sus profesores, los materiales pedagógicos y la estructura física utilizada para las clases. Se siguió una perspectiva histórica guiada por un análisis documental, así como un diálogo con tres docentes jubilados que emprendieron una carrera profesional como docentes de las materias en cuestión. Concluimos destacando la actualidad y proyecciones para el desarrollo de las disciplinas del Atletismo en los Cursos de Educación Física Licenciatura y Licenciatura del CEFD / UFSM, así como las acciones y proyectos que se encuentran en operación con la temática de ese deporte.

Palabras clave: Memoria; Atletismo; Plan de Estudios

\section{Introdução}

Prefaciando a clássica ${ }^{1}$ obra "Antologia do Atletismo: metodologia para iniciação em escolas e clubes", o primeiro professor visitante do Centro de Educação Física e Desportos da Universidade Federal de Santa Maria (CEFD/UFSM), Jürgen Dieckert, em 1983, argumenta que "Os fantásticos resultados obtidos em altura, distância e velocidade, [...], nada mais são do que a consequência do correr, lançar e saltar", ou seja, os frutos colhidos no quintal do Atletismo representam nada mais do que o bom trato e excelência no cuidado e desenvolvimento das manifestações corporais e habilidades básicas do movimento humano no plano da cultura e do fenômeno esportivo.

Sobre isso, Oro (1983) explica que a razão da existência e da socialização do Atletismo, seja nos bancos escolares ou fora deles, se justifica por três determinações que tornam essa modalidade mais acessível, quais sejam: a possibilidade de descoberta de algum tipo de aptidão esportiva, seja atleta ou praticante; o desenvolvimento e aprendizagem das destrezas técnicas e atléticas que são realizadas a partir da manifestação de movimentos básicos e naturais; e a não dependência de infraestrutura específica para o desenvolvimento de sua prática, uma vez que é viável, para sua realização, uma multiplicidade de formas e uma versatilidade de instalações e equipamentos adaptados.

\footnotetext{
${ }^{1}$ Clássica porque foi a primeira da série "Educação Física - Prática" a incluir um coautor brasileiro (Ubirajara Oro) dentro do projeto de tradução exclusiva de autores alemães (Dr. August Kirsch, ex-presidente da Federação Alemã de Atletismo, e Karl Koch, um dos principais especialistas de língua alemã no ensino dos esportes), implantado e inicialmente coordenado pelo Professor Visitante Dr. Jürgen Dieckert. Sua elaboração foi viabilizada a partir do apoio administrativo do CEFD/UFSM.
} 
Diante desses preceitos, este artigo tematiza a memória das disciplinas ${ }^{2}$ de Atletismo dos Cursos de Educação Física ${ }^{3}$ durante os 50 anos do CEFD/UFSM. Objetivamos, portanto, apresentar o desenvolvimento das referidas disciplinas no cinquentenário da referida Unidade de Ensino, trazendo para cena suas primeiras formas e sua organização curricular, a identificação de seus docentes, os materiais pedagógicos e a estrutura física utilizada para as aulas, a partir da exposição de três atores ${ }^{4}$ desse enredo: Hélio Fuke ${ }^{5}$, Ubirajara Oro $^{6}$ e Ivon Chagas da Rocha Junior ${ }^{7}$. Nossos atores são professores aposentados e contribuíram para o desenvolvimento do Atletismo no CEFD/UFSM.

O presente artigo se torna oportuno uma vez que pretende trazer à cena os traços históricos e rememorar os empreendimentos didático-pedagógicos que alicerçaram o desenvolvimento do CEFD/UFSM desde o ano de 1970 até nossos dias, e como o Atletismo com suas disciplinas foi sendo implantado e tendo seu desenvolvimento impulsionado em cada momento histórico. Este artigo possui a finalidade de preservar a memória da(s) disciplina(s) de Atletismo dos Cursos de Educação Física CEFD/UFSM, dessa forma, a memória nos atenta tanto à característica de lembrar experiências passadas como apoio para registros, mesmo sabendo que a mesma é dispersa, dinâmica, objeto de disputas e, portanto, passível de ressignificações, cuja elaboração é constantemente revivida, reelaborada e modificada (LINHALES; NASCIMENTO, 2013).

Para tanto, lançamos mão de uma base metodológica pautada por uma abordagem qualitativa numa perspectiva histórica, tendo em vista a apresentação de alguns registros e fatos históricos sobre o CEFD/UFSM e as referidas disciplinas, bem como a realização de um diálogo ${ }^{8}$ com os atores mencionados. Os dados apresentados e descritos no decorrer deste artigo foram captados em documentos institucionais,

\footnotetext{
${ }^{2}$ No que tange às acepções da palavra disciplina, nos referimos neste artigo a cada uma das unidades curriculares da matéria técnica Atletismo, cujo conteúdo costuma vir fracionado na grade de ensino (por exemplo, no ementário dos cursos superiores, o Atletismo é distribuído entre as disciplinas Atletismo I, Atletismo II, etc.).

${ }^{3}$ Estaremos fazendo referência ao Curso de Graduação em Educação Física de 1970 a 2005. O Curso de Graduação em Educação Física era denominado Licenciatura Plena até o ano de 2005, após houve a fragmentação em Licenciatura e Bacharelado.

${ }^{4}$ Justificamos a escolha dos três professores por fazerem parte do quadro docente do CEFD em diferentes períodos. Os demais professores efetivos que compuseram o quadro docente do Atletismo encontram-se in memoriam. Também destacamos que não utilizaremos, como de praxe acadêmica, nomes fictícios ao referirmo-nos às falas dos docentes, pois merecem visibilidade pelo longo e frutífero trabalho desenvolvido no Centro de Educação Física e Desportos - UFSM.

${ }^{5}$ Mestre em Educação Física pela Universidade Nacional de Tóquio. Ingressou como professor do CEFD/UFSM em 1975 permanecendo até 2002 .

${ }^{6}$ Doutor em Epistemologia da Motricidade Humana pela Faculdade de Motricidade Humana da Universidade Técnica de Lisboa. Ingressou como professor do CEFD/UFSM em agosto de 1979 e saiu em dezembro de 1982.

7 Doutor em Ciência do Movimento Humano pela Universidade Federal de Santa Maria (UFSM). Professor do Curso de Educação Física CEFD/UFSM desde 1993 até 2016.

${ }^{8}$ Para coleta dessas informações, em razão da dificuldade de acesso aos referidos participantes (atores) e do distanciamento social em despeito à prevenção da COVID-19, trabalhamos com duas possibilidades de instrumentos: em forma de questionário ou entrevista, a partir da disponibilidade do entrevistado. As questões elaboradas para nortear o diálogo tematizavam o movimento histórico do Atletismo no CEFD/UFSM desde a construção da pista, as primeiras organizações curriculares das disciplinas, espaços físicos e materiais didáticos até as mudanças curriculares mais atuais que seguiam as diretrizes formativas.
} 
como o Projeto Político Pedagógico dos Cursos de Educação Física, os Catálogos Gerais e Ementários da Graduação em Educação Física e as Fichas Cadastrais dos Docentes, pesquisados no Departamento de Arquivo Geral da UFSM. Consultados considerando a base curricular elaborada no intervalo de tempo entre os anos de 1970 e 2005, ano da última reformulação curricular vigente.

\section{O Atletismo nos Cursos de Educação Física do CEFD/UFSM: Investigações Históricas}

O Curso de Educação Física da UFSM iniciou suas atividades acadêmicas em 1970, sendo constituído especificamente por um departamento ${ }^{9}$, a saber: Departamento de Educação Física e Desportos (EDF), e tendo suas disciplinas curriculares distribuídas em seis semestres ou três anos de curso. O primeiro currículo do Curso de Graduação ${ }^{10}$ foi aprovado em 1971 pelo Conselho Universitário da UFSM, seguindo as normas do currículo mínimo para cursos de Educação Física, conforme Parecer nº 894 de 21 de dezembro de 1969, Resolução 2.069/69 do Conselho Federal de Educação (BRASIL, 1969). O currículo foi elaborado com o apoio de docentes da Universidade Federal do Rio de Janeiro (UFRJ) tendo como referência a grade curricular da Escola de Educação Física do Exército (EsEFEx), que predominou até 1973.

[...] o primeiro currículo do Curso de Graduação em Educação Física da UFSM foi elaborado com o apoio de docentes da Universidade Federal do Rio de Janeiro (UFRJ), seguindo a orientação do Conselho Federal de Educação (CFE) que, em consonância com a Reforma Universitária determinada pela lei 5.540/68, estabeleceu novas diretrizes para os currículos dos cursos de graduação em 1969. (CEFD, 2005, p. 3).

No período 1970 a 1973, a grade curricular do Curso era composta, dentre outras, por quatro disciplinas de Atletismo (Atletismo I, II, III e IV) contemplando conhecimentos teórico-práticos e, das três disciplinas de Arbitragem, uma contemplava a arbitragem em Atletismo (Arbitragem II - Atletismo e Tênis), totalizando uma carga horária de 210 horas (UFSM, 1973). Atribuímos a oferta de disciplinas que tematizavam o Atletismo a uma questão fundamental que ainda permeia a área e as atividades corporais oriundas das ações do movimento humano, qual seja: o Atletismo como "esporte base" para as demais modalidades. Ubirajara Oro (2020) ajuda-nos a compreender essa questão a partir de seu relato:

"Como ainda hoje sucede um pouco para todo lado, também no CEFD/UFSM o Atletismo era tido e havido como "esporte-base", por se constituir de modulações mais ou menos complexas das

\footnotetext{
${ }^{9}$ Vale lembrar que a partir da portaria 7677/74, de 12/08/74, foi criado o Departamento de Desportos Universitários, responsável pela administração da prática de Educação Física no Ensino Superior.

${ }^{10}$ Somente um curso naquele momento.
} 
formas básicas de movimento andar, correr, saltar, arremessar e lançar. Sendo a sua característica fundamental a medida, os seus fiadores eram o cronômetro e a fita métrica".

Vale destacar que as aulas práticas das referidas disciplinas, desenvolvidas nos anos de 1970 a 1972, eram realizadas em espaço externo à universidade, qual seja: a pista de Atletismo do $1^{\circ}$ Regimento de Polícia Montada de Santa Maria (Brigada Militar). Segundo o professor Ivon Chagas da Rocha Junior (2020):

"as primeiras aulas de Atletismo nas dependências do Centro de Educação Física ocorreram durante as ofertas do Curso de Verão ${ }^{11}$, realizadas no período de dezembro 1972 a fevereiro de $1973 ”$.

A partir de dezembro de 1972 o Centro de Educação Física passa a dispor de uma pista de Atletismo e campo de Futebol, seguindo o modelo do Memorial Descritivo (1969) e Especificações da Escola de Educação Física do Exército/RJ. Sua localização é anexa ao Estádio Tarso Dutra, sendo a primeira pista oficial do interior do Estado do Rio Grande do Sul, pavimentada com pó de carvão e possuindo setores de salto em altura, distância, arremesso de peso e lançamento de disco, martelo e dardo e um campo de futebol em seu interior - 104x70m. O professor Ubirajara Oro (2020) descreve com mais detalhes a estrutura da pista de Atletismo do CEFD/UFSM:

“O CEFD dispunha de instalações esportivas bastante qualificadas, em comparação com as da maioria das outras IES que ofereciam formação em Educação Física e Desportos no País. No caso particular do Atletismo, o estádio universitário tinha até mesmo arquibancada coberta. A pista de carvão adensado, com 400 metros de perímetro interno, comportava oito raias regulamentares na reta geral e seis em toda a volta, além de um "fosso" para as corridas com obstáculos (steeplechase ${ }^{12}$ ). A pista circundava um campo gramado para Futebol. No "espaço morto" entre a pista e o campo, havia tanque de areia grossa para os saltos de prevalência horizontal (em distância e triplo) - dotado de encaixe para a vara de salto, corredor para o lançamento do dardo, bem como (3) círculos pavimentados para o arremesso do peso e o lançamento do disco. Faltavam, apenas, uma gaiola de segurança para os lançamentos centrifugados (do disco e do martelo) e colchões de aterrissagem (ou "áreas de queda" feitas de espuma de petróleo) para os saltos de prevalência vertical (em altura e com vara)".

Para desenvolvimento das atividades das disciplinas, durante os períodos de chuvas e de baixas temperaturas era utilizado um espaço alternativo para a realização das modalidades de corridas e saltos, localizado no $3^{\circ}$ andar do Estádio denominado: "Pista Aérea", composta por três raias de 100 metros, com piso de cimento.

"Dia de chuva íamos para o terceiro piso, onde hoje são as salas de aula, tinha até raias no chão [...]” (Ivon Jr., 2020).

${ }^{11}$ O Curso de Verão representava a oferta de disciplinas no intuito de integralização curricular.

12 Denominação na língua inglesa para a corrida com obstáculos. 


\begin{abstract}
"Por vários anos tivemos o que chamávamos de "pista aérea", uma pista de 3 raias no piso de cimento no $3^{\circ}$ andar do estádio na parte interna, nos ajudava muito em dias de chuva e no inverno." (Fuke, 2020).

"Para além dessas instalações ao ar livre, o próprio feitio em curva do edifício que sustenta a arquibancada permitia a utilização de uma área semiaberta de concreto que era designada como "pista aérea", devido a ser o teto de uma parte das salas subjacentes do prédio. Ali eram ministradas aulas de corridas e de marcha, quando a pista de carvão ficava interditada por intempérie”. (Oro, 2020).
\end{abstract}

A partir da construção de salas de aulas no $3^{\circ}$ andar do Centro, em 1987, o espaço alternativo utilizado pelos docentes como forma de realização das atividades pedagógicas em dias de chuva e frio foram os ginásios didáticos. O professor Ivon Jr. (2020) relata com mais detalhes a utilização dos ginásios didáticos no seguinte trecho de sua exposição:

\begin{abstract}
"É importante levar em consideração que, por conta de instabilidade do clima, sempre foi necessário assegurar-se que haveria uma sala disponível para as sessões da disciplina. Porém, como seria impossível repetir em sala normal as atividades que deveriam ser trabalhadas nas instalações atléticas, de minha parte sempre tentei negociar espaços nos ginásios didáticos (em geral apenas utilizados pelos chamados esportes coletivos)".
\end{abstract}

A pista de Atletismo do CEFD/UFSM, além de ter se constituído como um espaço para o desenvolvimento de atividades didáticas e de pesquisas em níveis de graduação e pós-graduação ${ }^{13}$, também foi sede de várias competições, contemplando diferentes segmentos: universitárias, escolares e militares a nível municipal e intermunicipal - Jogos Intermunicipais do Rio Grande do Sul, regional e estadual, bem como sendo ponto de referência para treinamento de atletas e equipes do interior do Estado. É meritório registrar que entre 1979 e 1982 o CEFD/UFSM sediou e geriu uma edição bastante concorrida dos Jogos Universitários Gaúchos de Estudantes de Educação Física. Além dessas atividades, a pista de Atletismo do CEFD/UFSM foi palco de inúmeros projetos de extensão, como: Festival de Atletismo Escolar, Clubes Universitários (atual Esporte Universitário), Mercomovimento (cursos, clínicas e oficinas), entre outros. O professor Ubirajara Oro (2020) explica como eram alguns eventos e o engajamento dos professores e acadêmicos:

\footnotetext{
${ }^{13}$ Destacamos, nesse processo, os seguintes laboratórios de pesquisa do CEFD/UFSM: Laboratório de Biomecânica, Laboratório de Fisiologia do Exercício, Laboratório de Performance em Ambiente Simulado e Laboratório de Cineantropometria.
} 


\begin{abstract}
"No periodo abrangido por estas memórias, todos os próprios professores do CEFD tinham oportunidade de, ao menos uma vez por ano, renovar as suas "vivências atletísticas", participando da corrida rústica de aniversário do CEFD, ao longo das ruas do Campus de Camobi, com saída e chegada na pista do estádio universitário, à maneira da maratona dos Jogos Olímpicos. [...]. Graças à disposição incansável do Prof. Dalcione Rambo (CEFD), os alunos da Licenciatura em Educação Física da UFSM recebiam uma sólida formação técnica em arbitragem de competições, baseada na prática continuada em eventos escolares e também militares, frequentemente em finsde-semana”.
\end{abstract}

Segundo os atores participantes de nosso estudo, os materiais didáticos disponibilizados eram suficientes para o exercício da docência, no que tange aos implementos, estes apresentavam uma padronização oficial da categoria adulta vinculada ao aparelhamento das competições oficiais. Vejamos como os professores Ivon Jr. (2020) e Ubirajara Oro (2020) elucidam essas questões:

"[...] sempre, desde o inicio, se teve boas condições em termos de material, com problemas pontuais como: - aparelharam o CEFD como se fosse um clube federado, com pesos oficiais de implementos. Por exemplo, dezenas de pesos com $4 \mathrm{~kg}$ e 7,260 kg, ou seja, os oficiais para a categoria adulta. Nenhum peso de 2, 3,5,6 kg, para crianças e jovens. Discos, dardos e martelos idem. As barreiras pioneiras não eram ajustáveis e não tinham contrapeso, portanto em uma competição não poderiam ser batidos recordes." (Ivon Jr.).

\begin{abstract}
"Quanto aos equipamentos, nomeadamente os implementos requeridos pelas várias disciplinas do Atletismo, o almoxarifado do Departamento de Desportos Individuais (DDI) dispunha de material suficiente e até farto. Digno de menção, pelo seu valor pedagógico, era o costume (que, aliás, não vi em nenhum outro local em que atuei!) de os alunos retirarem no almoxarifado o material para uso durante a aula e ai o devolverem depois de ela concluida." (Oro).
\end{abstract}

Outro fato que marcou o movimento de existência do Atletismo no CEFD foi a composição das turmas em naipes masculino e feminino. Nesse interim, o termo naipes denota um fato histórico que era a fragmentação de uma turma de 50 alunos em duas turmas de 25 alunos: Turma 11 (T 11) feminina e Turma 12 (T12) masculina. Sobre isso, os professores Hélio Fuke (2020) e Ubirajara Oro (2020) explicam que:

\begin{abstract}
"Desde o início até um determinado período os atletismos eram divididos em turmas masculinas e femininas, 111 feminina e 12 masculina, com 25 vagas para cada turma. As cargas horárias eram as mesmas para T11 e T12. Os conteúdos eram os mesmos divididos entre teórica e prática”. (Fuke).

“As turmas de graduação do CEFD vinham separadas por naipe, em femininas e masculinas. Com
isso, procurava-se nivelar a condição para o desempenho nas aulas práticas, o que era coerente
com aquela sua concepção. [...]. Nas disciplinas que eu ministrava para as alunas de graduação,
incluí conteúdos do programa olímpico masculino da IAAF ${ }^{14}$. À maneira mais pragmática, eu
\end{abstract}

${ }^{14}$ Nomenclatura utilizada na época. Historicamente, o estatuto da Federação Internacional de Atletismo Amador ("primeira" e pioneira IAAF, sediada em Estocolmo) prevaleceu de 1912 até 2001, quando foi alterado e resultou na Associação Internacional 
entendia que as licenciandas tinham direito à mesma informação profissional que os licenciandos. Aliás, assim já funcionava no curso de especialização, em que as turmas eram mistas, ao contrário do curso de licenciatura". (Oro).

Os primeiros docentes responsáveis pelo ensino das disciplinas de Atletismo (I, II, III e IV) foram: Clóvis Monteiro Ávila, formado pela Escola de Educação Física do Exército, atuante no período de 1970 a 1981; Cecy Funck Rubin, formada pela Escola Superior de Educação Física da Universidade Federal do Rio Grande do Sul, atuante no período de 1970 a 1975, e Pedro Luiz Beno Lang, formado pela Escola Superior de Educação Física da Universidade Federal do Rio Grande do Sul, atuante no período de 1970 a 1974.

Nesse contexto, importa salientar que os primeiros professores ${ }^{15}$ de Atletismo do CEF/UFSM, sem exceção, atuavam ou haviam atuado como treinadores de Atletismo nas principais escolas da educação básica de Santa Maria - RS, com os Professores Clóvis M. Ávila e Cecy F. Rubin. Da mesma forma, atuaram em clubes de Porto Alegre, com destaque para a Sociedade de Ginástica de Porto Alegre (SOGIPA), com o Professor Pedro Lang. Em sequência, vieram os professores Hélio Fuke (1975), formado pela Escola Superior de Educação Física da Universidade Federal do Rio Grande do Sul, e Ubirajara Oro (1979), formado pela Escola Superior de Educação Física da Universidade Federal do Rio Grande do Sul (ESEF/UFRGS). Vale destacar que ambos também atuaram como treinadores no âmbito escolar da rede básica. Hélio Fuke foi treinador na SOGIPA e Ubirajara Oro foi atleta federado na mesma instituição.

A partir dos anos 1980, ingressaram no quadro docente do CEFD/UFSM os professores Dalcione Paulo Rambo (1980) e Ivon Chagas da Rocha Júnior (1993) para atuarem, especificamente, nas disciplinas de Atletismo em substituição à aposentadoria dos professores pioneiros. Ambos formados pelo Centro de Educação Física e Desportos - UFSM, na terceira turma, em 1974, bem como atuantes na rede básica de ensino de Santa Maria - RS e técnicos de Atletismo da equipe do referido município. No ano de 2004, em função da aposentadoria do professor Hélio Fuke, ingressou no quadro docente do CEFD/UFSM a professora Carmen Lúcia da Silva Marques, formada pelo Centro de Educação Física e Desportos - UFSM, em 1993, atuando com as disciplinas de Atletismo I e II do Curso de Educação Física Licenciatura até o ano de 2013. Ainda sobre a atuação profissional da professora Carmen Lúcia da Silva Marques, destacamos seu compromisso político-pedagógico no que se refere às mudanças de paradigma teórico-metodológico para o ensino-aprendizagem e desenvolvimento do Atletismo na tentativa de superação da lógica da aptidão

de Federações de Atletismo ("segunda" IAAF, sediada em Londres). Isso sucedeu por força da profissionalização crescente dos atletistas e culminou, desde outubro de 2019, na recente World Athletics (WA, sediada em Mônaco).

15 Os dados referentes à carreira profissional dos referidos professores foram obtidos via Ficha Cadastral do Servidor DAG/UFSM. 
física. Seu empreendimento profissional visava minimizar a lógica de ensino (lógica competitiva) que predominava no CEFD/UFSM até então ${ }^{16}$.

Cabe registrar que as disciplinas de Atletismo tiveram, em determinados períodos, a atuação de professores substitutos, em função de aposentadorias e afastamento para aperfeiçoamento na formação, quais sejam: Ivana Maria Lambert Miotti, Jacob Alfredo Iora, Mônica Possebon e Daniela Sastre Rossi Visintainer. Destacamos que os respectivos professores realizaram grandes contribuições para o ensino das disciplinas de Atletismo e mantiveram a relevância do referido esporte na formação inicial de professores.

No ano de 1971 a UFSM se tornou a primeira instituição do País a atender o Decreto ${ }^{\circ} 69.450$ do Governo Federal, que tinha como objetivo a criação de clubes universitários (em diversas modalidades esportivas) para os estudantes do ensino superior (BRASIL, 1971). Dessa forma, foi criada a disciplina CEF 100, vinculada ao Departamento de Desportos Universitários (DDU), sendo ofertada a todos os estudantes do ensino superior da UFSM, os quais poderiam escolher diferentes esportes para a sua prática obrigatória. Essa disciplina permaneceu sendo exigida por no mínimo dois semestres até o ano de $1997^{17}$ (UFSM, 1997), realizando poucas contribuições no que se refere à formação de equipes, tanto no Atletismo como em outras modalidades esportivas. Os professores Ivon Jr (2020) e Hélio Fuke (2020) explicam que:

“[...] tampouco o CEF 100 servia como celeiro/peneira de atletas. Nunca houve tentativa, por exemplo, de formar equipes representativas, sejam universitárias ou federadas. Pouco antes de um JUGs se reunia os melhores atletas da UFSM, ex-atletas estudantis em sua maioria. Não havia uma preparação sistemática, com horários e planejamento de treinos”. (Ivon Jr).

"A contribuição do atletismo com CEF100 foi muito pouco. Eram mais uma atividade obrigatória para a prática da Ed. Física por 2 semestres. Pela falta de vagas em outras modalidades como vôlei, natação, ginástica, as mais procuradas, se matriculavam no atletismo. Poucos eram os que realmente optavam por esta modalidade e que já tinham alguma noção do que era o atletismo". (Fuke).

\footnotetext{
${ }^{16}$ Com isso, não queremos dizer que a referida professora tenha sido a única a empreender um movimento de superação da lógica competitivista e da aptidão física do CEFD/UFSM, tampouco que tal lógica tenha sido, de fato, superada. Entretanto, o reconhecimento da atuação e do compromisso assumido pela professora Carmen Lúcia da Silva Marques é inegável, basta visitarmos uma de suas produções acadêmicas desenvolvida em parceria com o Professor Jacob Alfredo Iora (professor substituto das disciplinas de Atletismo I e II do CEFD/UFSM de 2013 - 2015) para conhecermos um pouco de sua concepção profissional, sobretudo no que se refere ao ensino do Atletismo. Artigo intitulado: ATLETISMO ESCOLAR: POSSIBILIDADES E ESTRATÉGIAS DE OBJETIVO, CONTEÚDO E MÉTODO EM AULAS DE EDUCAÇÃO FÍSICA (MARQUES; IORA, 2009), disponível em: https://seer.ufrgs.br/Movimento/article/view/3078.

${ }^{17}$ Resolução no 018 de 1997. Dispõe sobre a desobrigatoriedade de cursar a disciplina de Educação Física pelos alunos dos Cursos de Graduação da UFSM.
} 
No que se refere às ementas das disciplinas, no início da criação do Centro, mencionamos os conteúdos ${ }^{18}$ : Atletismo I - Técnica de aprendizagem de execução das provas de corridas, velocidades e arremessos; Atletismo II - Técnica de aprendizagem de execução das provas de corridas de fundo e saltos; Atletismo III - Processos pedagógicos - técnica e tática de corridas de velocidades, meio fundo e arremessos; Atletismo IV - Processos pedagógicos - técnica e tática das corridas de fundo e saltos (UFSM, 1973).

Analisando as grades curriculares e ementas do curso de Educação Física desde os anos 1970, observou-se que em 1974 houve uma ampliação da carga horária das disciplinas de Atletismo, perfazendo um total de 300 horas (75h/disciplina). Justifica-se tal ampliação em função da inclusão das modalidades de arremesso de martelo ${ }^{19}$, corrida com obstáculos e revezamentos com obstáculos na disciplina de Atletismo III. Em 1976 observa-se mudanças nas ementas das disciplinas com a implementação de 'processos metodológicos' dos conteúdos de cada unidade ofertada, ou seja, desde as primeiras disciplinas de Atletismo (atletismo I e II) já havia a preocupação com o conhecimento das metodologias de ensino das modalidades, acarretando determinada ruptura ou atenuação do caráter tecnicista que pautava as ações pedagógicas até então.

No mesmo período, verifica-se também a inclusão de modalidades com diferentes características, como: corridas, saltos e arremessos, na mesma unidade/disciplina (UFSM, 1976). Nesse bojo, o conteúdo das disciplinas de Arbitragem (I, II e III) passou a ser desenvolvido nas disciplinas relativas ao esporte correspondente, isto é, a disciplina de Arbitragem II, que tratava sobre a arbitragem em Atletismo e Tênis, por exemplo, foi suprimida e seu conteúdo passou a ser desenvolvido na própria disciplina das referidas modalidades. Do mesmo modo, foi constatada a existência de pré-requisitos para as disciplinas de Atletismo II, III e IV, que predominou até os anos 1980. Nesse caso, a título de exemplo, a disciplina de Atletismo I era pré-requisito para disciplina de Atletismo II e assim sucessivamente.

Em 1976, o Curso de Pós-Graduação oferta Especialização em Técnicas Desportivas na modalidade de Atletismo, possibilitando um aprofundamento em metodologias de ensino, treinamento desportivo e pesquisa. O curso perfazia um total de 450 horas e perdurou até 1982. Após esse período surgiu a Especialização em Educação Física Escolar. Destacamos o protagonismo do professor Hélio Fuke, pois sua dedicação ao Atletismo possibilitou-lhe traçar altos voos no plano da pós-graduação na qualidade de orientador de diversas monografias, como menciona o professor Ubirajara Oro (2020):

\footnotetext{
${ }^{18} \mathrm{Na}$ sequência será exposto um quadro comparativo e mais detalhado com os conteúdos e outras categorias que constituíram o Atletismo do CEFD/UFSM desde os anos 1970 até os dias atuais.

${ }^{19}$ Nomenclatura utilizada na época. Atualmente utiliza-se Lançamento do Martelo.
} 


\begin{abstract}
"Por sua vez, o Prof. Fuke tinha uma dedicação praticamente exclusiva ao Atletismo, quer na licenciatura quer na especialização. De longe, foi ele o principal orientador de conteúdo das centenas de monografias produzidas pelos alunos dos dois níveis nessa matéria. Ademais da sua relevante contribuição ao desenvolvimento do Atletismo junto à UFSM, o Prof. Fuke terá reforçado o legado social dessa modalidade a partir da UFSM, como docente solicitado por outras IES para cursos e atividades formativas similares". (Oro).
\end{abstract}

A Pós-Graduação em Atletismo contribuiu para qualificar o Curso de Graduação em Educação Física, sobretudo na formação em aspectos técnicos, pedagógicos e científicos, como também proporcionou para os acadêmicos espaços do processo de aprendizagem e profissionalização. Isso ocorreu uma vez que se ampliou e aprofundou o rol de investigação científica, elaboração de eventos e atividades acadêmicas e a vinculação de professores referência para a área.

Na década de 80 houve uma mudança na organização do Curso de Graduação em Educação Física. Com o novo Estatuto Universitário, a partir das adaptações exigidas pela sessão no 240, do dia 29/07/78, conforme o processo ${ }^{\circ}$ 51.475/78, o Centro de Educação Física passou a se denominar Centro de Educação Física e Desportos (UFSM, 1978). Até então o Curso de Educação Física estava lotado em apenas um departamento (DEF), com a departamentalização ${ }^{20}$ em âmbito geral das universidades, passou a ser sistematizado em três departamentos, a saber: DEC - Departamento de Desportos Coletivos; DEI Departamento de Desportos Individuais; e MTD - Departamento de Métodos e Técnicas Desportivas. Nessa reestruturação, que acarretou numa redistribuição das disciplinas da graduação, o Atletismo ficou lotado no DEI. O desenvolvimento das disciplinas de Atletismo no CEFD/UFSM durante os anos 1980 não apresentou grandes impactos estruturais ou conceituais e manteve sua organização distribuída em quatro disciplinas (Atletismo I, II, III e IV) (UFSM, 1980).

Em 1991 21 , a duração do Curso de Graduação em Educação Física foi ampliada de seis para oito semestres $^{22}$. Com a nova reformulação da ementa do Curso, as disciplinas de Atletismo passaram a ser denominadas de Esporte Individual conforme descrição no quadro 1:

Quadro 1: Distribuição das disciplinas de Esporte Individual

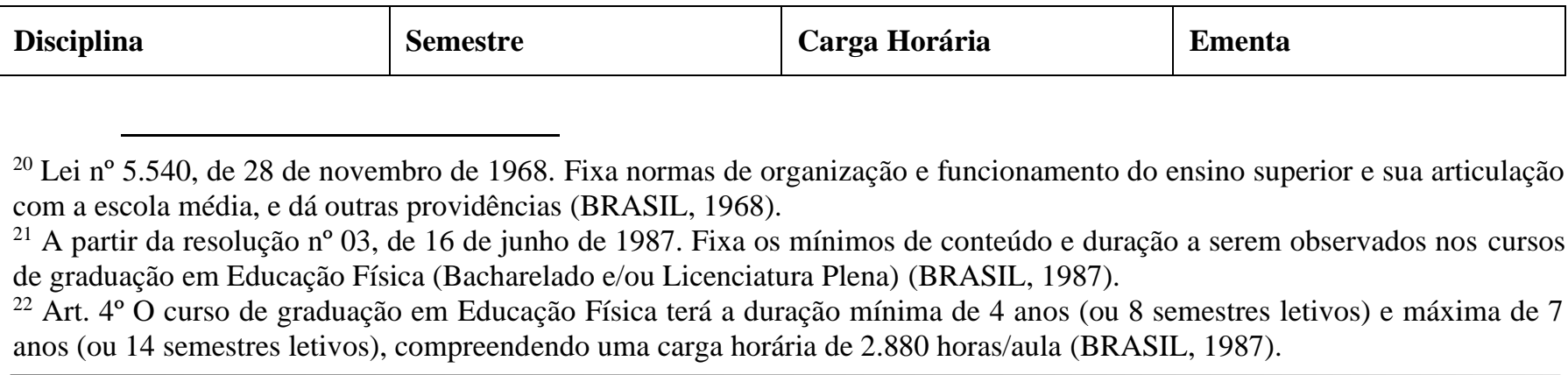




\begin{tabular}{|l|l|l|l|}
\hline Esporte Individual I & $2^{\mathrm{o}}$ & $45 \mathrm{~h}$ & $\begin{array}{l}\text { Noções Básicas de provas } \\
\text { Atléticas e Características } \\
\text { Gerais das Provas Atléticas; }\end{array}$ \\
\hline Esporte Individual II & $4^{\mathrm{o}}$ & $60 \mathrm{~h}$ teórico/prática & $\begin{array}{l}\text { Corridas, Saltos, Arremessos } \\
\text { e Lançamentos; }\end{array}$ \\
\hline Esporte Individual III & $6^{\circ}$ & $60 \mathrm{~h}$ teórico/prática & $\begin{array}{l}\text { Saltos, lançamentos, corridas, } \\
\text { marcha e provas combinadas; }\end{array}$ \\
\hline
\end{tabular}

Fonte: UFSM (2005)

Em 2004, o Currículo do Curso de Educação Física do CEFD/UFSM, orientado pelas Diretrizes Curriculares Nacionais (DCNs), como prescreve a LDB 9.394/96 no Art. 53․ II: "fixar os currículos dos seus cursos e programas, observadas as diretrizes gerais pertinentes" (BRASIL, 1996), passa por nova reestruturação (BRASIL, 2004). Diante disso, o CEFD apresentou dois novos cursos de formação de profissionais em Educação Física, o Curso de Licenciatura, com início no primeiro semestre de 2005 e o Curso de Bacharelado, com início no primeiro semestre de 2006.

Nesse contexto, as disciplinas de Esporte individual (I, II e III) passaram novamente a ter a denominação de Atletismo, sendo o Atletismo I e II, ambos com 60h, divididas em teórico-práticas. A cada Curso (Licenciatura e Bacharelado) foi atrelado duas disciplinas de Atletismo (I e II), com os conteúdos voltados ao seu campo de atuação (CEFD, 2018a; 2018b). A antiga disciplina de Esporte Individual I, que apresentava as Noções Básicas de Provas Atléticas e Características Gerais das Provas Atléticas, antes obrigatória, permaneceu com a sua nomenclatura, mas transformou-se em uma Disciplina Complementar de Graduação (CEFD, 2005).

\section{Presente e Futuro: o Atletismo no CEFD/UFSM}

Atualmente os professores efetivos que atuam nas Disciplinas de Atletismo dos Cursos de Licenciatura e Bacharelado em Educação Física do CEFD/UFSM, lotados no Departamento de Desportos Individuais, são nomeadamente: Luiz Fernando Cuozzo Lemos (2017) e Leandra Costa da Costa (2018), ambos formados pela Universidade Federal de Santa Maria.

Através dos referidos professores, as disciplinas de Atletismo dos cursos de Educação Física do CEFD/UFSM vêm sendo revividas a partir de ações vinculadas à tríade universitária: ensino, pesquisa e 
extensão. O professor Luiz Fernando criou o Núcleo de Implementação da Excelência Esportiva e Manutenção da Saúde (NIEEMS), com isso surgiu a equipe de Atletismo da UFSM. A referida equipe é filiada à FAERGS (Federação de Atletismo do Estado do Rio Grande do Sul) e à CBAt (Confederação Brasileira de Atletismo), participando assim de competições a nível estadual, nacional e internacional. Simultaneamente, a equipe participa também de campeonatos universitários, sendo bicampeã dos JUGs (Jogos Universitários Gaúchos) em suas duas participações.

Responsável pelas disciplinas de Atletismo I e II do Curso de Educação Física Licenciatura, a professora Leandra coordena o Festival de Atletismo, um projeto de extensão, que ocorre semestralmente nas dependências do CEFD/UFSM juntamente com os acadêmicos da turma de Atletismo II. Esse evento fornece às escolas e estudantes da cidade e região a possibilidade de conhecer e vivenciar as modalidades do Atletismo, difundindo o conteúdo e propiciando o desenvolvimento do esporte. Também possui projeto de ensino que, através do Programa de Licenciaturas (PROLICEM), busca fornecer os subsídios necessários para o desenvolvimento de uma proposta de ensino do Atletismo nas escolas. Da mesma forma, orienta projetos de pesquisa ligados ao Fundo de Incentivo à Pesquisa (FIPE) que tematiza o Atletismo no contexto escolar e acadêmico.

Em relação à infraestrutura para o desenvolvimento das atividades das referidas disciplinas, o CEFD, em 2018, foi contemplado com recursos do Programa da Rede Nacional de Treinamento, da Secretaria Nacional de Esporte de Alto Rendimento, do Governo Federal, com uma pista de Atletismo que deixará de ser de carvão batido, e passará a ser de material sintético, oficial e com o padrão Olímpico, de acordo com os padrões da Federação Internacional de Atletismo. Além disso, o CEFD também obteve a modernização dos seus laboratórios de pesquisa, a fim de fornecer os subsídios necessários para o treinamento de atletas de alto rendimento. O Projeto da nova pista foi registrado no Portal de Projetos (050354) viabilizado através dos esforços conjuntos do professor Luiz Fernando, do NIEEMS, da Administração Central da UFSM e do Ministério do Esporte ${ }^{23}$.

\section{Referências}

BRASIL. Parecer CNE/CES n. 0058, de 18/02/2004: Institui as diretrizes curriculares nacionais para os cursos de graduação em educação física, em nível superior de graduação plena. Brasília, 2004. Disponível em: http://portal.mec.gov.br/cne/arquivos/pdf/2007/pces058_04.pdf. Acesso em: 03 jul. 2020.

\footnotetext{
${ }^{23}$ Neste ponto é importante destacar a figura do Secretário Nacional do Esporte de Alto Rendimento, Luiz Celso Giacomini, professor e diretor aposentado do Centro de Educação Física e Desportos-UFSM.
} 
BRASIL. Ministério da Educação. Conselho Nacional de Educação. Lei de Diretrizes e Bases da Educação Nacional n. ${ }^{\circ}$ 9394/96, de 20 de dezembro de 1996. Disponível em: http://www.planalto.gov.br/ccivil_03/leis/19394.htm. Acesso em 29/06/2020.

BRASIL. Conselho Federal de Educação. Resolução no 03/88-CFE. Fixa os mínimos de conteúdo e duração a serem observados nos cursos de graduação em Educação Física (Bacharelado e/ou Licenciatura Plena). Brasil, 16 de junho de 1987.

BRASIL. Decreto ${ }^{\circ}$ 69.450, de $1^{\circ}$ de Novembro de 1971. Regulamenta o artigo 22 da Lei $\mathbf{n}^{\circ}$ 4.024, de 20 de dezembro de 1961, e alínea c do artigo 40 da Lei no 5.540 , de 28 de novembro de 1968 e dá outras providências. Brasília, DF, novembro de 1971.

BRASIL. Conselho Federal de Educação. Parecer n ${ }^{\circ} 894$ de 21 de dezembro de 1969, Resolução 2.069/69. Currículo mínimo para cursos de Educação Física, dezembro de 1969.

BRASIL. Lei $n^{\circ} 5.540$, de 28 de novembro de 1968. Fixa normas de organização e funcionamento do ensino superior e sua articulação com a escola média, e dá outras providências. Brasília, DF, junho de 1968.

CENTRO DE EDUCAÇÃO FÍSICA E DESPORTOS. Programa da disciplina de Atletismo I. Centro de Educação Física e Desportos/UFSM. Santa Maria, 2018a. Disponível em: https://portal.ufsm.br/documentos/publico/documento.html?id=8789193. Acesso em: 29 jul. 2020.

CENTRO DE EDUCAÇÃO FÍSICA E DESPORTOS. Programa da disciplina de Atletismo II. Centro de Educação Física e Desportos/UFSM. Santa Maria, 2018b. Disponível em: https://portal.ufsm.br/documentos/publico/documento.html?id=8788959. Acesso em: 29 jul. 2020.

CENTRO DE EDUCAÇÃO FÍSICA E DESPORTOS. Projeto Político Pedagógico do Centro de Educação Física e Desportos. Universidade Federal de Santa Maria. Santa Maria, 2005.

DIECKERT, Jürgen. Prefácio. In: KIRSCH, August, KOCH, Karl, ORO, Ubirajara. Antologia do Atletismo: metodologia para iniciação em escolas e clubes. Rio de Janeiro: Ao Livro Técnico, 1983.

HÉLIO FUKE. Entrevista concedida aos autores. 2020.

IVON CHAGAS DA ROCHA JÚNIOR. Entrevista concedida aos autores. 2020.

LINHALES, Meily Assbu; NASCIMENTO, Adalson (Orgs.). Organizando arquivos, produzindo nexos: a experiência de um Centro de Memória. Belo Horizonte: Editora Fino Trato, 2013.

ORO, Ubirajara. Iniciação ao Atletismo no Brasil: problemas e possibilidades didáticas. In: KIRSCH, August, KOCH, Karl, ORO, Ubirajara. Antologia do Atletismo: metodologia para iniciação em escolas e clubes. Rio de Janeiro: Ao Livro Técnico, 1983.

UBIRAJARA ORO. Entrevista concedida aos autores. 2020.

UFSM. RESOLUÇÃO N. 018/1997. Dispõe sobre a desobrigatoriedade de cursar a disciplina de Educação Física pelos alunos dos Cursos de Graduação da UFSM. Gabinete do Reitor da Universidade Federal de Santa Maria. Santa Maria, dezembro de 1997. 
UFSM. Catálogo/Ementário 1980. Santa Maria: UFSM, 1980.

UFSM. Estatuto Universitário n $^{2}$ 240, processo no 51.475/78. Santa Maria, 29 de julho de 1978.

UFSM. Catálogo Geral 1976. Santa Maria: UFSM, 1976.

UFSM. Catálogo 1973. Santa Maria: UFSM, 1973.

\section{Como citar este artigo}

COSTA, L. C.; SALDANHA FILHO, M. F; SCAPIN, G. J; ROSSI JÚNIOR, N. A Memória do Atletismo nos Cursos de Educação Física da Universidade Federal de Santa Maria. Revista Kinesis, Santa Maria, Dossiê CEFD 50 anos, p.01-15, 2020.

* O presente trabalho não contou com apoio financeiro de nenhuma natureza para sua realização. 